\title{
ALGUNAS CONVENCIONES DEL TEATRO CALDERONIANO EN LOS LIBRETOS DE APOSTOLO ZENO
}

\author{
Miguel Martín Echarri \\ C/ Castelar 43, $1^{\circ}$ dcha \\ 39004, Santander, España \\ mrtnchrr@gmail.com
}

\section{INTRODUCCIÓN}

La obra dramática del veneciano Apostolo Zeno (1668-1750) no defrauda las expectativas de quien se acerca a ella con los presupuestos que ha construido la historiografia literaria: se trata de un escritor teatral digno de la imagen del reformador dieciochesco, que diseña los libretos de acuerdo con una preceptiva bastante inflexible ${ }^{1}$. Tiene claro lo que no desea para el teatro, rechaza los excesos del barroquismo, desde los finales sangrientos racinianos hasta los atentados contra el decoro de los graciosos lopescos. Se suma, además, a una corriente que empezó antes que él a criticar y atacar los desmanes del melodrama de la época y sigue también la línea de aquellos que intentaban «restaurar» la perfección perdida del teatro clásico.

Sin embargo, contra lo que cabría esperar, en su obra podemos encontrar ciertas convenciones habituales en el teatro de Calderón de la Barca, uno de los máximos exponentes de la dramaturgia barroca. Se trata de un fenómeno interesante porque, pese al rigor con que Zeno atacó los excesos del teatro musical barroco, precisamente el más declaradamente afin a

${ }^{1}$ Para un resumen de su biografia y significado en la historia de la ópera, ver Di Felice, 1997. Sobre la importancia de su reforma, entre otras obras generales de historia de la ópera, puede consultarse Kimbell, 1991, pp. 181-205. 
la comedia áurea española, obviamente no estaba empeñado en renunciar a todo elemento capaz de provocar un efecto teatral provechoso.

\section{UN EJEMPLO}

Griselda (1701) recrea la última novella del Decamerone de Boccaccio (X, 10): el rey Gualtiero de Tesalia (en Boccaccio era solo marqués de Saluzzo) se ha casado con una mujer de baja cuna, Griselda, y se ve obligado a renunciar a ella para evitar una sublevación, pues los prejuicios de sus súbditos les impiden ver la calidad moral de su esposa, por lo que exigen una reina de alcurnia. Él ha decidido ponerla a prueba para demostrar a su pueblo su elevación moral: la somete a múltiples humillaciones que ella resiste sin faltar a la fidelidad hasta que el pueblo aclama su perfección y es devuelta al trono.

La historia no fue tratada por Calderón, pero en el segundo acto de la ópera nos encontramos una situación que se repite en el teatro calderoniano: Griselda, expulsada al bosque, se ha quedado dormida bajo un árbol, y su hija Oronta, a quien ella cree muerta, llega y se la encuentra hablando en sueños, dirigiéndose precisamente a su hija muerta, la misma Oronta. De este modo, se da un diálogo que los dos interlocutores creen imposible y sin embargo el público reconoce como indudablemente verdadero y efectivo:

\section{Oronta, e Griselde che dorme}

OrONTA

[...] Anco entro a questa

vil capanna... che miro!

Donna sù letto assisa e dorme e piange.

Come in rustico ammanto

volto hà gentil! Sento in mirarla un forte

movimento dell'alma. Entro le vene

s'agita il sangue, e il cuor mi balza in petto.

GRISELDA

Oronta

GRISELDA
Vieni...

Dormendo

M'apre le braccia, e al dolce amplesso

il suo sonno m'invita;

il mio cor mi consiglia.

Non resisto più nò.
Ahime!
Si leva $a^{2}$.

Diletta Figlia.

${ }^{2}$ Zeno, Griselda, p. 40. 
$\mathrm{Y}$ es que en Calderón encontramos múltiples ejemplos en que un personaje escucha palabras que no van dirigidas a él pero adquieren un significado preciso. Unas veces él mismo es capaz de interpretar esas palabras, otras es solo el público el que sabe que todo se cargará de sentido en algún momento. El espectador sabe que, de acuerdo con una convención, lo que es un error dentro de la diégesis responde no obstante a una ignorada necesidad fuera de ella. En La gran Cenobia, un ejemplo entre tantos, la protagonista se retira un momento de la batalla para vendarse una herida, y escucha las voces que profiere Astrea, que ha sido arrojada a una sima por Aureliano, voces que se ajustan perfectamente a su situación:

Cenobia

De la batalla rendida, sin que me hayan conocido, sola a este monte he salido para curarme una herida, en cuya ofensa ha de ser teatro este monte fuerte, romanos, de vuestra muerte.

Dentro Astrea quejándose.

ASTREA ¡Ay, infelice mujer!

Cenobia Parece que oigo, jay de mí!, turbada una voz, que dice que soy mujer infelice ${ }^{3}$.

Todavía se escucha a Astrea en varias intervenciones que valen tanto para su propia suerte como para la de Cenobia. Naturalmente, el público entiende que todo lo que "al acaso» se le vaticina al personaje terminará por cumplirse.

Este tipo de parlamento descontextualizado presenta en el corpus calderoniano diversas variantes. El ejemplo corresponde a la escucha casual de palabras ajenas sacadas de su contexto, pero no faltan ejemplos, similares al de Zeno, en que lo que se escucha es un parlamento dicho en sueños por el otro personaje, lo que adquiere un valor de verdad superior, ya que en sueños no se miente. Así, en Darlo todo y no dar nada, Apeles busca a su amada Campaspe y, aunque está dormida en escena, no la encuentra, pero a sus preguntas contesta ella como un eco: sus

${ }^{3}$ Calderón de la Barca, La gran Cenobia, pp. 349-350. 
palabras son respuestas, pero a la vez son un discurso coherente, aunque entrecortado, en forma de ovillejos:

\begin{tabular}{|c|c|}
\hline APELES & {$[\ldots]$ ¿Murió en faltándola yo? } \\
\hline CAMPASPE & [Entre sueños] \\
\hline APELES & ¿Tuvo, cuando ausente estuve... \\
\hline CAMPASPE & ... tuve... \\
\hline Apeles & ... quien venciese en su disculpa? \\
\hline CAMPASPE & . la culpa.. \\
\hline APELES & ¿Qué eco a mi voz respondió? \\
\hline CAMPASPE & ...уов. \\
\hline Apeles & $\begin{array}{l}\text { ¡Cielos!, ¿si es verdad o no, } \\
\text { que el aire me ha respondido? } \\
\text { pues ha sonado en mi oído... }\end{array}$ \\
\hline Los DOS & ... no tuve la culpa yo ${ }^{4}$. \\
\hline
\end{tabular}

\section{3. НipótesIS}

Tanto en Griselda como en otras obras de Zeno encontramos estos y otros recursos de curioso parentesco con los de Calderón, que nos llevan a plantear una hipótesis: que el conocimiento que Zeno tenía de la obra de Calderón no se limitaba a la influencia de la comedia española en el teatro musical italiano, ni siquiera a la transmisión de los textos españoles traducidos o deformados, sino que disponía de las competencias lingüísticas y del material necesario para un conocimiento de primera mano, lo que le permitió aprovechar algunos de los recursos más habituales de su teatro en la construcción de sus libretos.

La obra del español vivía la resaca de su anterior éxito internacional y empezaba a ser despreciada por preceptistas y autores teatrales: el propio Zeno no lo menciona ni siquiera en el prólogo de una obra como su Scipione nelle Spagne, escrita para la corte barcelonesa del aspirante austriaco al trono español, el Archiduque Carlos de Habsburgo, basándose en fuentes clásicas que ya habían inspirado a Calderón El segundo

${ }^{4}$ Calderón de la Barca, Darlo todo y no dar nada, p. 1043. 
Scipión; ni en el de Semiramide in Ascalona, sobre un episodio utilizado para La hija del aire: Zeno reconoce las fuentes clásicas, pero no explica por qué la que en Diodoro era hija de Nino aparece como su hermana y por qué Ones (Menón en Calderón) se llama Mennone en Zeno. Pero no nos proponemos discutir la posibilidad de una influencia directa en títulos concretos, pese a que el conocimiento de esos antecedentes por parte del veneciano es más que probable.

Es curioso que un autor en quien se ha visto el ejemplo de utilización y reconocimiento responsable de las fuentes cite con excepcional lealtad a sus antecesores franceses o italianos en el tratamiento de ciertos argumentos (así Maximian de Corneille o Iphigénie de Racine) ${ }^{5}$ e ignore a Calderón. Posiblemente hay que entender que Zeno no se basó en ningún argumento del español, pese a las evidentes coincidencias, o bien que era ya una fuente que prefería no reconocer. Los estudios posteriores sobre Zeno y su obra tampoco atienden a esta posibilidad: ni la biografia de $\mathrm{Negri}^{6}$ ni otros estudios más recientes ${ }^{7}$.

Sin embargo, en la biblioteca privada de nuestro libretista, que hoy se conserva en la Libreria Marciana de Venecia, se puede consultar un ejemplar de la primera edición de autos sacramentales que el dramaturgo español publicó en 1677 (149 D 126). Que ese volumen pertenecía a Apostolo Zeno es indudable porque aparece recogido en el catálogo de sus libros que él mismo realizó y se conserva en la sección de manuscritos de la misma biblioteca (Codice marciano It. XI, 287). Claro que no es posible garantizar que lo hubiera leído, ya que no hay evidencias fisicas en el ejemplar: una mano anónima ha corregido un error en la página 232 (una intervención del Amor que viene equivocadamente atribuida a la Culpa), pero es posible que se trate de una corrección de otro dueño del mismo libro, tal vez cierto Don Julio del Rosal y Estrada que firma la primera página, probablemente anterior a la adquisición de Zeno (ya que el tomo no volvió a España).

Obviamente, la coincidencia de cualquier convención dramática entre la obra de Zeno y alguno de estos autos tendrá un valor añadido frente al resto de la obra calderoniana, si bien su ausencia tampoco invalida otros hallazgos.

\footnotetext{
${ }^{5}$ Van Der Linden, 2007, p. 387.

${ }^{6}$ Negri, Vita di Apostolo Zeno.

${ }^{7}$ Freeman, 1981; Strohm, 1997; Van Der Linden, 2007.
} 


\section{Condiciones de la posible lectura CAlderoniana}

Considerando la evolución general de la obra de Zeno a la luz de su biografia, en ningún punto se advierte un cambio de estética brusco, sino una evolución paulatina: es en sus primeras obras donde se da una mayor concentración de convencionalismos en mayor o menor medida coincidentes con los de la escuela calderoniana, y progresivamente se percibe un intento de buscar una teatralidad más pura, inspirada seguramente por los dramaturgos franceses ${ }^{8}$. Puede decirse que va despojando su teatro de la parte más ornamental del formalismo teatral para acercarse poco a poco a conflictos más sencillos pero siempre eficaces. Lo que se mantiene a lo largo de toda su obra es el cuidado diseño de las tensiones, algo que también comparte con el dramaturgo español.Y su creciente inquietud es asegurar en todo momento la perfección moral de los personajes y la exactitud histórica de la trama.

Es poco probable que Zeno haya ignorado las obras de Lope y de Calderón a través de las traducciones hechas por los dramaturgos de las generaciones anteriores. Sin lugar a dudas, conocía los libretos que tenían más éxito en su tiempo, entre los que destacaban los de Cicognini, traductor de Calderón que aprovechó algunos de sus rasgos más espectaculares a la hora de elaborar sus libretos, especialmente en Il Giasone (1649), con música de Cavalli, una verdadera conmoción en su época. Se trata de la obra inaugural del melodrama veneciano, género hegemónico en la escena europea durante la segunda mitad del s. XVII: algo más parecido a un espectáculo de variedades débilmente vertebrado por una trama mitológica. La renuncia a la unidad argumental, o de género, la falta de respeto al decoro, las caóticas entradas y salidas de todo tipo de personajes, así como los bruscos saltos temporales, son rasgos que Cicognini justificó aludiendo al Arte nuevo de Lope y contra los que Zeno y los demás reformadores se posicionaron firmemente.

Ese enfrentamiento prueba entonces el conocimiento por parte de nuestro libretista de esa tradición indirecta basada en las refundiciones, tradición que indudablemente desdeñaba. Pero no debemos olvidarnos del evidente conocimiento directo de su obra que se esforzó en cultivar, como prueba el hecho de que adquiriera el mencionado ejemplar de

${ }^{8}$ De hecho, frente a la única presencia del volumen de autos de Calderón y de otro de poesía lírica de Lope de Vega (V 55), se encuentran en el catálogo de la biblioteca de Zeno múltiples referencias a los dramaturgos franceses, entre ellos Pierre Corneille (C 142-147) o Racine (R 5). 
los autos sacramentales (aunque ignoremos la fecha de la adquisición y de la presunta lectura). Por otro lado, del mismo modo que es imposible asegurar, a partir del hecho de que un libro estuviera en su posesión, que Zeno efectivamente lo hubiera leído, también es necesario reconocer como probable que el interés que esa posesión demuestra implique el conocimiento de otros volúmenes con sus obras, especialmente en una época en que el costo de los libros era necesariamente elevado.

Debemos entender entonces que, en la época en que el melodrama sacaba muchos de sus recursos del teatro español, Zeno pudo hacer un esfuerzo por conocer las fuentes originales, dejando a un lado las versiones deformadas de los refundidores italianos, con lo que su labor teatral, incluso dentro de la reforma, no tenía por qué dejar de sacar partido de aquellos recursos provenientes de la comedia española cuando le convenían.

Es cierto que algunos de estos estereotipos aparecían también en obras de otros dramaturgos españoles contemporáneos de Calderón, pero debe desestimarse su importancia porque su trascendencia en la cultura italiana fue siempre menor que la de Lope y Calderón y porque solo este último está representado en el catálogo de la biblioteca privada de Zeno.

Tampoco parece que Zeno haya tomado esas convenciones de la tradición veneciana del libreto, porque el grado de sofisticación que alcanzan en su obra se asemeja más al repertorio de Calderón que a un supuesto intermediario que desaprovecha las posibilidades de tales hallazgos. El ejemplo ya citado del diálogo con un dormido es un estereotipo que emplea también Cicognini. En Il Giasone, II, 2, Oreste e Isifile son quizás más sinceros de lo que hubieran sido en caso de que ella hubiera estado despierta, pero no hay ninguna sugerencia extradiegética, mientras que Zeno sí parece tener a la vista las posibilidades de la idea y las sabe aprovechar: las palabras de Griselda dormida son válidas para Oronta despierta, quien cree sin embargo que no lo son; el público tiene derecho a empezar a sospechar con ese diálogo que la verdadera identidad de Oronta la incapacita para el matrimonio con Gualtiero, que en realidad es su padre. Es decir que este tipo de diálogos, además de la multiplicidad de sentidos que admiten en Zeno y en Calderón, constituyen un momento clave en la trama, que no pierde intensidad por el juego (lo que sí ocurre en Cicognini). Como apuntábamos, una entidad extradiegética se dirige al espectador desde las palabras trascendiendo las identidades de los personajes que las enuncian. 
Pero no podemos perder de vista que las obras que presentan un mayor número de este tipo de elementos son las más primerizas de Zeno, incluyendo Gl'inganni felici (1695) o Faramondo (1699), y que a medida que su técnica se afianza va renunciando a ellos, por más que siempre quede algún engaño, alguna falsa identidad en casi todas las obras, atavismos de un estilo de la confusión poco a poco condenado.

Si volvemos entonces a la extrañeza inicial de que el reformador racionalista que pide la unidad y la adecuación a las reglas parezca volver la vista al más barroco de los dramaturgos españoles, podemos reconsiderar la situación desde una perspectiva sutilmente diferente: por un lado, se trataría de una influencia de juventud bastante generalizada en la Italia de su tiempo, por lo que él no se consideraría abanderado de una estética particular sino que utilizaría elementos en boga y a mano de cualquiera (en este sentido es muy diferente del caso de Cicognini, que sí defendía su alianza con los dramaturgos españoles); por otro lado, la reforma tiene sentido porque Zeno se esfuerza por eliminar los rasgos externos más barrocos que había introducido Cicognini —el bufón que interviene en la acción, las múltiples tramas sin relación pero que se interrumpen permanentemente, los personajes de varias procedencias sociales, la ubicuidad de la música, el continuo cambio de espacio o los bruscos saltos temporales - para quedarse con la pureza dramática (simetría, estructura, ciertos trucos dramáticos, situaciones climáticas).

En realidad, no debería sorprendernos que, abocado a trabajar en un género teatral que despreciaba (su verdadera vocación era la de historiador), utilizase los recursos de cualesquiera autores que estaban a su alcance, aunque fuera rechazando otros rasgos de esos mismos autores que a él le parecieran excesivos.

\section{Las CONVENCiOnes CALderonianas en el teatro de Zeno}

No prestaremos atención a las múltiples diferencias que se encuentran entre el teatro de uno y otro, y que no dejan de declarar la independencia de Zeno como autor dramático y su evolución con el paso del tiempo. Se deben a la necesidad de adecuación a medios diferentes como son el teatro hablado y el melodrama, pero también a la lealtad a estéticas diversas.

Por otro lado, hay parecidos estructurales entre los dos que no necesariamente delatan el conocimiento de uno por parte del otro, como el frecuente esquema en tres actos o la cuidada arquitectura dramática, 
prioridad máxima en ambos, que asegura la funcionalidad de todo fragmento en la trama.

Pero sí son un aspecto revelador de intertextualidad algunos de los estereotipos calderonianos que se pueden encontrar en la obra de Zeno. Consideramos que en Zeno aparecen piezas del mecano que Calderón construía en cada comedia, elementos dinámicos que por su eficacia dramática permiten asegurar el éxito de una obra, sea para prestar más atención a sutilezas formales o filosóficas, o simplemente para facilitar su composición.

Naturalmente, no se trata de un juego de alusiones, porque Zeno no se dirigía a un público lector de Calderón, sino más bien del aprovechamiento de recursos teatrales demostradamente eficaces, al menos en el ámbito de un código ya estabilizado.

Claro que es posible encontrar otras procedencias para algunos de esos recursos, pero hay que reconocer que el teatro francés que servía de referente en el momento perseguía una sobriedad mayor, y las convenciones de la Tragédie en musique, por ejemplo, son muchas pero otras. Algo parecido puede decirse del teatro italiano coetáneo. En cualquier caso, lo llamativo es la reiteración y concentración de estas coincidencias, independientemente de que algunas puedan resultar más débiles que otras, o bien menos específicas de la comedia española.

Vamos a describir ahora algunas de estas convenciones que aparecen en la obra de Zeno, dando ejemplos significativos tomados de Calderón $\mathrm{y}$, siempre que sea posible, de alguno de los autos recogidos en el tomo de 1677 que poseía Zeno.

\section{a) Contrapunto}

Como primer ejemplo, recordamos los paralelismos en el lenguaje del fragmento citado al principio, ya que encontramos en Zeno diálogos que podríamos llamar "contrapuntísticos», tomando el término de la teoría musical (dos frases musicales que suenan simultáneamente). El discurso de un personaje es interrumpido por la intervención de otro, para continuar después donde lo había dejado, produciéndose un efecto de simultaneidad. Es cierto que el procedimiento no es exclusivo del teatro calderoniano, si bien en algunas obras de Calderón aparece llevado a grados de enorme complejidad gracias a la combinación de varias conversaciones que se alternan. Entre los muchos ejemplos que se encuentran en los autos de 1677, ofrecemos uno de El nuevo hospicio de pobres: 
REY

Apostasía

REY

Apostasía

REY

Apostasía

REY

Apostasía

REY

Apostasía

REY
¿Y cómo aquí...

¡Qué pavor!

... entraste...

¡Qué sentimiento!

... sin haber...

¡Qué ansia! ... lavado...

¡Qué parasismo!

... primero...

¡Qué angustia!

en la sangre del cordero

que cruento sacrificio

fue, para ser incruento?

Ya Cicognini adaptaba este recurso en Il Giasone, aunque no con la ligereza que Zeno sabe recoger en esta conversación de Gl'inganni felici, en que Alceste, que en realidad es Oronta disfrazada de un astrólogo de ese nombre, lee la mano de Sifalce:

Sifalce Le linee osserva...

Alceste

(O mia

dolcissima omicida!)

SifALCE ... teco stesso, che parli $^{10}$;

\section{b) Correlación}

En la misma obra, encontramos también correlaciones en el sentido definido por Alonso ${ }^{11}$, como esta en que Armidoro y Sifalce han descubierto que, debajo de sus disfraces y encubiertas intenciones, se disputan a la misma dama:

${ }^{9}$ Calderón de la Barca, El nuevo hospicio de pobres, pp. 212-213.

10 Zeno, Gl'inganni felici, p. 16.

${ }^{11}$ Alonso, 1976, p. 389. 
Armidoro Ecco Sifalce.)

SifALCE

Ecco Armidoro.)

Armidoro

$\mathrm{O}$ quale

ira,

SifALCE

O qual'odio,

ARMidoro

in sen mi bolle?

SifALCE

io sento?

À 2

Forse ch'è mio Rival, ma no'l pavento ${ }^{12}$.

Este es uno de los rasgos más distintivos del estilo calderoniano, que se encuentra en todas sus obras.

\section{c) Apartes}

Este ejemplo sirve también para ilustrar el uso tan sofisticado del aparte que hace el autor en su primer libreto, basado, como los de Calderón, en un entramado de paralelismos que permiten seguir el hilo pese a la confusión. La situación común de los enamorados permite que sus frases compartan la misma sintaxis o incluso el mismo léxico, así como interrupciones contrapuntísticas.

Desde luego, los apartes no son una invención de Calderón, pero su uso sistemático y combinado con los contrapuntos y las correlaciones sí supone un rasgo característico de su dramaturgia.Y es esta misma combinación la que encontramos en los libretos de Zeno.

Existe una variante más sofisticada: un personaje se dirige a varios interlocutores, cada uno de los cuales parece escuchar versos alternos, siendo el público el único que oye todo lo que se dice. Dado que entre los doce autos de 1677 no se encuentra este recurso, volvemos la vista a las comedias: en Duelos de amor y lealtad Toante, disfrazado de jardinero, estaba conversando con Irífile cuando llegan Zenón y Leónido por distintos lugares y sin verse entre sí. Irífile se ve obligada a mantener una conversación de apartes con los tres, para lo cual finge estar recogiendo flores: eso le permite acercarse de vez en cuando a Toante y decirle fragmentos de frases que luego deberá reunir para entender el sentido. Esos fragmentos están incluidos en el discurso que dirige a uno u otro enamorado:

12 Zeno, Gl'inganni felici, p. 38. 

IRÍFILE
¿Quién está aquí?
ZENÓN
Quien con verte
está engañando sus ansias.
IRÍfILE Volveré por otra parte.
ZENón ¿Quién a huir te obliga?
IrífILE (Al pasar por junto a Toante, diga el medio verso, $y$ así los demás, que él repite) Deidamia.
TOANTE «Deidamia», al pasar me dijo ${ }^{13}$.

Entonces se dirige a Leónido, y el artificio sigue esta mecánica de un interlocutor a otro hasta que Irífile consigue transmitirle los cinco versos necesarios para que Toante sepa que Deidamia piensa sacarla de Tiro ocultamente y devolverle la libertad, por lo que él debe esperar resignado a que ella vuelva a salvarle.

En Il Teuzzone, de Zeno, Zidiana ha decidido aprovecharse de dos cortesanos que están enamorados de ella, y en un solo monólogo se dirige a ambos, haciendo creer a uno que engaña solo al otro, cuando el público sabe que en realidad alberga la esperanza de seducir a un tercero, el legítimo heredero, protagonista de la obra.

Siverino (A Cino $)$ Lascia ch'io teco adempia il dover di vasallo.

CinO

Anzi di amico.

Siverino Mio Re, t'inchino.

Cino

In amistà ti abbraccio.

Zidiana (E due così prendo ad un laccio.)

(A Cino) Sarai mio: (A Sivenio) (Lo dico a te,)

(A parte) (E a chi parlo, Amor lo sa.)

( $A$ Cino) Tu mio sposo, (A Sivenio) E tu mio Re, servi al fasto, ed all'amore.

( $A$ parte) (Sol chi regna in sul mio core, meco il trono ancor godrà $)^{14}$.

13 Calderón de la Barca, Duelos de amor y lealtad, p. 1478.

${ }^{14}$ Zeno, Il Teuzzone, p. 109. 
Se trata de un caso de barroquismo ejemplar, que incluye una pequeña correlación entre las declaradas intenciones de Cino y Siverino al principio. En un género como el melodrama, la textura debe ser mucho más condensada que en el teatro hablado, dado que toda palabra aparece dilatada por la adaptación al recitativo cantado, lo cual explica la diferencia de extensión entre los dos fragmentos comparados.

Por otro lado, una estructura argumental suficientemente ordenada y simétrica es condición inexcusable para la utilización de esta técnica. Tanto en Calderón como en Zeno se producen conflictos paralelos capaces de albergar correlaciones prolongadas que constituyen uno de los principios estructurales de toda la escritura de autos sacramentales de Calderón, sin excluir ninguno de los de 1677. Ejemplar puede ser la escena inicial de La vida es sueño, en que aparecen los cuatro elementos disputándose la corona del mundo hasta que la trinidad representada por el Poder, la Sabiduría y el Amor pone orden.

\section{d) Intervenciones «al acaso»}

Entre esos autos sacramentales sí encontramos múltiples ejemplos de respuestas descontextualizadas que adquieren significados nuevos, como la que ya hemos citado de Griselda. Así, por recurrir al ejemplo más obvio y reiterativo, en La vacante general, la Sinagoga y el Judaísmo se preguntan indignados a quién podrían concederse las prebendas vacantes al quedar obsoleta la ley hebraica en el nuevo orden religioso de la Ley de Gracia. $\mathrm{Su}$ pregunta retórica encuentra una respuesta procedente de otro carro:

JuDAÍSMO

$[\ldots]$ ¿Quién puede ser cabeza de ella?

Da vuelta el primer carro que será una barca, y vense en ella Pedro con el timón, Andrés con la vela y Juan y Diego con los remos, y mientras representan a lo lejos dan vueltas navegando.

ANDRÉs

$$
\text { Pedro, }
$$

cuidado con el timón, pues te ha tocado el gobierno de aquesta pequeña nave en que tormentas corremos ${ }^{15}$.

${ }^{15}$ Calderón de la Barca, La vacante general, pp. 351-352. 
La situación se repite para dar una respuesta y una función en la nueva Iglesia de Cristo a cada uno de los apóstoles.

Hay otros ejemplos similares en estos autos, pero no encontramos ninguno que implique parlamentos dichos en sueños por un dormido, como era el caso en Griselda y en Darlo todo y no dar nada.

\section{e) El impostor que habla de sí mismo}

Dejamos las convenciones estilísticas para entrar en rasgos de la trama, circunstancias reconocibles en los argumentos.

La intercambiabilidad de dos personajes en una escena o una obra completa permite calcos del lenguaje en sus intervenciones, a condición de simplificar en cierta medida sus psicologías, que se someten a la trama por una función que cumplen de acuerdo con una caracterización conflictiva elemental puesta en evidencia desde su primera aparición. Aunque tan simples como quepa imaginar, los dos cortesanos de Zidiana son perfectamente capaces de desequilibrar el statu quo inicial, como en tantas comedias de Calderón, por no hablar de sus autos sacramentales, en que toda caracterización se limita a la descripción del concepto, evitando caer en un exceso de complejidad que rompería la fidelidad al género.

Esto es lo que permite que haya equívocos, personajes disfrazados (característica en general muy extendida en la comedia, no solo en la española), como los que ya veíamos en Gl'inganni felici, y también en Il Teuzzone, cuando Zelinda, enamorada y amada por el legítimo heredero que da título a la obra, finge conocer a Zelinda como si fuera otra persona, lo que le permite acercarse a la usurpadora Zidiana para descubrir sus verdaderas intenciones bajo el pretexto de ayudarla. Aquí la tenemos hablando de sí misma desde otra identidad:

ZeLINDA Il suo core non è facil trofeo, Zelinda il tiene:

Zelinda, a cui già tempo diè nel Tartaro ciel fede di sposa ${ }^{16}$.

No de otra forma actuaba el Toante en Duelos de amor y lealtad, cuando se fingía Estratón en casa de su enemigo Leónido, lo mismo que Eugenia en El José de las mujeres o el rey Lidoro en La hija del aire, que

${ }^{16}$ Zeno, Il Teuzzone, p. 131. 
se hace pasar por Arsidas en la corte de su enemigo Nino para lograr el amor de su hermana Irene. Pero este artificio ocupa una posición central en la segunda parte, cuando la reina secuestra a su hijo Ninias para sustituirlo. Cuando las diferencias de carácter empiezan a ser evidentes, finge una afinidad filial:

Semíramis Semíramis es mi reina, mi señora y mi madre, y cuantas sospechas de ella se fingen, lo mismo a mí que a ella agravian ${ }^{17}$.

En un sentido más amplio, aunque no hagan referencia directa a sus verdaderas identidades como si fueran ajenas, un personaje aparece en un ámbito desconocido con un nuevo nombre en Gl'inganni felici, Atenaide y otras, del mismo modo que en Calderón en muchos momentos.

Pese a la multitud de personajes que en los autos de la edición de 1677 se disfrazan de otros o usurpan identidades ajenas (como la Malicia que expulsa a la Inocencia y se hace pasar por ella en La viña del Señor o la Lascivia que se finge doncella fugitiva de dos bandidos con la intención de seducir al Hombre y robarle en La nave del mercader), tampoco hemos encontrado este estereotipo llevado hasta el extremo descrito de que el disfrazado hable de sí mismo, fundamentalmente debido a las limitaciones argumentales que impone el género del auto sacramental.

\section{f) El escondido que malinterpreta}

También en Zeno los personajes se esconden para escuchar (lo que en la comedia española se llama quedarse «al paño») pero no entienden bien lo que presencian o escuchan, recurso generador de un equívoco fatal en El médico de su honra, cuando el rey Don Pedro ha hecho esconderse a Don Gutierre para que el infante don Enrique no lo vea y suponga las quejas que lo traían: la sospecha de que el infante ha seducido a su mujer. Don Enrique empieza a confesar una intención no realizada, pero el rey se lo estorba, de modo que la imaginación de Don Gutierre vuela, empujándolo al asesinato por ese error:

Don EnRique $\quad[. .$.$] Yo, señor, quise a una dama$ (que ya sé por quién lo dices,

${ }^{17}$ Calderón de la Barca, La hija del aire, p. 785. 
si bien con poca ocasión):

en efecto, yo la quise

tanto...

REY

¿Qué importa, si ella

es beldad tan imposible...?

Don EnRIQue Es verdad, pero...

REY

Callad.

Don EnRIQue Pues, señor, ¿no me permites disculparme?

REY

No hay disculpa;

que es belleza que no admite objeción.

Don ENRIQUe

Es cierto, pero

el tiempo todo lo rinde,

el amor todo lo puede.

Rey [Aparte] ¡Válgame Dios, qué mal hice

en esconder a Gutierre!

Callad, callad. [...]

Don Gutierre [...] ¡Vágame Dios! ¿Qué escuché?

Mas ¿para qué lo repite

la lengua, cuando mi agravio

con mi desdicha se mide?

Arranquemos de una vez

de tanto mal las raíces.

Muera Mencía; su sangre

bañe el pecho donde asiste ${ }^{18}$;

De modo parecido, aunque incruento, en Atenaide, una de las últimas obras del libretista, el rey de Persia Varane se convence de que la protagonista lo sigue prefiriendo a él frente al emperador bizantino Teodosio porque, desde un escondite, la oye decirle a su padre:

$\begin{array}{ll}\text { Atenaide } & \text { Padre, } \\ \text { chi temuta in Teodosio } \\ \text { avria tanta ingiustizia? }\end{array}$

${ }^{18}$ Calderón de la Barca, El médico de su honra, pp. 454 y 457. 
VARANe (La mia Atenaide è questa, e del rival si lagna, e il chiama ingiusto. $)^{19}$

Eso es lo que lo envalentona y lo justifica en el delito de raptarla.

Otras veces la escucha sirve para descubrir secretos o deslealtades, como en Semiramide in Ascalona, en que la protagonista descubre que Mennone está dispuesto a casarse con otra. En Gl'inganni felici, Agarista llega donde está Alceste (en realidad, Oronta disfrazada) y escucha su parlamento:

Agarista Alceste, Alceste? In sù le molli piume tacito ò posa, ò dorme, e mesto parmi che dal duol non respiri ancor dormendo.

Folto nembo di pianti cade da gli occhi ancor che chiusi, e irriga i pallori del volto.

AlCeste Oronta, Oronta e vivi ancor?

AgARISTA

Che ascolto?

AlCESTE Chiudi gli occhi per sempre. A che più aprirli a imagini funeste?

A te sempre è infelice ed il nome di Oronta, e quel di Alceste.

Agarista Tanto duol fa pietà.

Alceste Che veggio? Oh Dio! Alceste alzando gl'occhi, e veduta Agarista tosto risorge Principessa, tù qui ? $^{20}$

Entonces Alceste descubre su verdadera identidad ante la dama, y ambas se declaran lealtad y auxilio en la consecución de sus fines, en absoluto excluyentes: cada una de ellas ama a un hombre distinto. Pero Armidoro (en realidad, Orgonte) llega a tiempo de ver el beso con el que las dos sellan su alianza, y como Oronta sigue disfrazada de Alceste

${ }^{19}$ Zeno, Atenaide, p. 233.

${ }^{20}$ Zeno, Gl'inganni felici, p. 44. 
la toma por un hombre y considera el beso dentro de la categoría amorosa, con lo que la trama vuelve a complicarse.

Este ejemplo nos permite introducir una nueva variante del malentendido, la que se produce a partir de gestos mal interpretados. También en El médico de su honra el rey Don Pedro hace entrega a su hermano el infante Don Enrique de la daga que lo compromete (la ha perdido en la casa de Don Gutierre), pero al tomarla hiere accidentalmente la mano del rey, quien lo interpreta como una evidente tentativa de agresión.

Un similar malentendido con una daga tiene lugar en Gianguir: vemos a Semira entrar en escena inadvertidamente en el momento en que Cosrovio, de rodillas, le ha entregado la espada a su padre el rey Giuanguir, de tal manera que interpreta inmediatamente que este quiere matar a su propio hijo: «SEMIRA: [Che veggo! Il figlio a pie' del padre? e in mano / al padre il ferro ignudo? $]^{21}$.

Aunque hay muchos escondidos en los autos (generalmente los aliados del Demonio), en ningún caso se produce la incomprensión característica de la comedia de enredo, de modo que también en este caso tenemos que suponer la lectura por parte de Zeno de otras obras de Calderón para explicar esta coincidencia.

\section{g) Comienzos estereotipados}

Un apartado importante del repertorio de convenciones compartidas es el de los inicios de los dramas o de los conflictos.

En Il Teuzzone, la confusión inicial de una batalla abre directamente el conflicto cuando el moribundo rey Troncone designa a su heredero, lo que será el origen de la trama:

Troncone Nostro, amici, è il trionfo. Ingo, il ribello cadde; e la pace al nostro Impero è resa.

Ruoti or la falce, e tronchi i miei stami vitali invida Parca; quello, di mie vittorie l'ultimo è de' miei dì. Più nobil fine non poteami dal Cielo esser prescritto. Si applauda.Vissi assai, se moro invitto ${ }^{22}$.

${ }^{21}$ Zeno, Gianguir, p. 271.

${ }^{22}$ Zeno, Il Teuzzone, p. 93. 
También Pirro empieza con una batalla sangrienta de la que acaba de salir victorioso el protagonista. Es lo mismo que ocurría en Fineza contra fineza o La hija del aire.También es el recurso empleado por Calderón en En la vida todo es verdad y todo mentira, en que el tirano Focas aprovecha su última victoria para contar públicamente su vida y sus intenciones inmediatas.

$\begin{array}{cl}\text { ElLA Y MÚsICA } & \begin{array}{l}\text { El nunca vencido Marte, } \\ \text { el siempre vencedor César } \\ \text { a los montes de Trinacria } \\ \text { en hora dichosa venga. }\end{array} \\ & \text { Las cajas } \\ & \text { Fuerza es que en hora dichosa } \\ & \text { venga, hermosa Cintia bella, } \\ \text { Focas } & \begin{array}{l}\text { quien viene a lograr aplausos } \\ \text { donde pensó hallar ofensas }\end{array}\end{array}$

Hay otras situaciones estereotipadas para originar el drama o servir de pretexto para las explicaciones necesarias que lo pongan en marcha. Svanvita se abre con un discurso del rey al pueblo, igual que en Griselda y en la escena triunfal con que arranca Scipione nelle Spagne, tópico que volveremos a encontrar en obras tan tardías como Gianguir, de 1724. Encontramos estas entradas solemnes en muchos autos, cuando el Demonio, en alguna de sus encarnaciones escénicas, convoca a sus aliados para organizar la caída del Hombre, o también cuando Dios Padre se dirige a los suyos para llevar a cabo la creación o la donación del libre albedrío al Hombre.

Sea el Demonio o Dios Padre, típicamente, el mismo personaje que hace su entrada solemne inmediatamente después convoca a otros personajes o les explica un proyecto, como vemos en El nuevo hospicio de pobres, cuando el Rey hace público que ha decidido promover la boda entre su hijo y la Sunamitis (que representa la Naturaleza Humana).
REY
[...] Determino darle estado [a mi hijo]
y para que resplandezca
en la elección de la esposa
más mi amorosa clemencia
ha de ser la Sunamitis ${ }^{24}$.
${ }^{23}$ Calderón de la Barca, En la vida todo es verdad y todo mentira, p. 22.
${ }^{24}$ Calderón de la Barca, El nuevo hospicio de pobres, pp. 81-84. 
Algo similar ocurre en No hay instante sin milagro, en que la Fe y la Apostasía discuten sobre la persistencia de los milagros y la primera propone una serie de ejemplos que se representan delante de su antagonista como demostración.

FE $\quad[\ldots]$ volvamos atrás los siglos,
y la paridad corriendo
de lo visible a invisible,
sea el ejemplo primero
la primera que me dio
asunto para el ejemplo

A continuación aparece Magdalena, como primer ejemplo que utilizará la Fe para convencer a la Apostasía. Es cierto que en este ejemplo la muestra ocurre en un nivel diferente de la diégesis, cosa que nunca ocurre en los melodramas de Zeno, pero eso no hace más que volverlo todavía más ejemplar.

En estos casos, la muestra no supone ninguna incógnita para el que ya conoce el final, pero es frecuente en este teatro que implique una prueba en la que se puede fracasar o triunfar. Es lo que ocurre en el auto La vida es sueño, cuando el Poder explica que ha decidido poner a prueba a su hijo el Hombre, a pesar de que la Sabiduría le ha hecho ver que caerá víctima del Pecado y la Sombra. Esto es común a la comedia La vida es sueño, de la cual está calcado el argumento teológico, y otro tanto puede decirse de otras muchas obras calderonianas, entre las que pueden destacarse En la vida todo es verdad y todo mentira o El gran teatro del mundo.

El inicio de Griselda comparte varios de estos rasgos, incluyendo la presencia de un público dentro de la diégesis al que se encomienda la supervisión de la prueba: también en La vida es sueño se trata de la corte.

Gualtiero Questo o Popoli è il giorno in cui le leggi da voi prende il Rè vostro: a voi fâ sdegno veder ch'empia il mio letto donna tratta da' boschi, donna avvezza a trattar rustica vanga: tal Griselda a me piacque, tal la sdegnaste. Alfine miro lei co' vostr'occhi.

${ }^{25}$ Calderón de la Barca, No hay instante sin milagro, pp. 90-92. 
Decretato è il ripudio, e voi ne siate giudici, e spettatori: Or che la rendo alle natie sue selve col vostro amor quel del mio core emendo ${ }^{26}$.

Pese a las diferencias argumentales, Svanvita se abre con un discurso de Olao igualmente dirigido al pueblo, esta vez para designar al nuevo rey, Roderigo. Sus razones son aclamadas, pero provocan reticencias en los apartes de varios personajes.

\section{h) Otras}

Por supuesto, hay muchas convenciones calderonianas que no hemos encontrado en ninguna de las obras estudiadas de Zeno, como la caída del caballo o el sueño premonitorio, del mismo modo que Zeno parece haber inventado otras que se repetirán en la opera seria: el enamorado que debe callar para salvar a la persona amada aunque eso le cueste perderla, por ejemplo.

En general se advierte que con el paso del tiempo el autor renuncia a escenas tan estereotipadas y busca situaciones más particulares dentro de la austeridad del nuevo estilo. Es cada vez más frecuente que la obra no presente más trama que el desarrollo de una situación climática, lo que se emparenta menos con el arte de Calderón y más con el de Racine.

\section{Conclusiones}

Todos estos ejemplos muestran que Apostolo Zeno no utilizaba los rasgos más externos y reconocibles de Calderón, es decir aquellos por los que se desataban polémicas en el mundo del teatro: todo lo que se discutía en torno a la poética de Aristóteles y la de Boileau. En esto, Zeno no dejó de acercarse a la estética francesa a lo largo de su obra, con lo que sus obras están en perfecta sintonía con los ideales del absolutismo imperantes en la Europa de principios del siglo XVIII.

Sin embargo, bajo la bandera de esa reforma racionalista, nada le impedía seguir recurriendo en la práctica teatral a aquellos elementos que demostraban una y otra vez su validez siempre que no estuvieran en contradicción con la primera, de modo que pudieron mantener su eficacia dramática engastados en nuevos mecanismos.

${ }^{26}$ Zeno, Griselda, p. 4. 
La condensación de este tipo de elementos convencionales en la obra de Calderón alcanza un carácter plenamente estructural, hasta el punto de haberse convertido en un código capaz de apoyar o generar nuevos significados dramáticos. Por eso resulta mucho más convincente la posibilidad de que, habituado a sus textos por las refundiciones y libretos de óperas, y conocedor directo de su obra por la lectura de volúmenes en español como el que se molestó en adquirir para su biblioteca, Apostolo Zeno decidiera utilizar todas esas convenciones en sus propios libretos, asimilándolas con todo su dinamismo y teatralidad (que es lo que con mayor frecuencia se había perdido en las versiones operísticas de Cicognini y sus seguidores), lo que explicaría la llamativa presencia de todo ese repertorio de convenciones calderonianas en la obra del gran detractor del Barroco. 


\section{BiBLIOGRAFÍA}

Alonso, Dámaso, "La correlación en la estructura del teatro calderoniano", en Calderón y la crítica: historia y antología, II, ed. Manuel Durán y Roberto González Echevarría, Madrid, Gredos, 1976, pp. 388-454.

Calderón de la Barca, Pedro, Darlo todo y no dar nada, en Obras completas, II, ed. Ángel Valbuena Briones, Madrid, Aguilar, 1987, pp. 1019-1067.

Calderón de la Barca, Pedro, Duelos de amor y lealtad, en Obras completas, II, ed. Ángel Valbuena Briones, Madrid, Aguilar, 1987, pp. 1459-1503.

Calderón de la Barca, Pedro, El José de las mujeres, en Obras completas, II, ed. Ángel Valbuena Briones, Madrid, Aguilar, 1987, pp. 905-938.

Calderón de la Barca, Pedro, El nuevo hospicio de pobres, ed. Ignacio Arellano, Kassel, Reichenberger, 1995.

CALderón de la BARCA, Pedro, No hay instante sin milagro, ed. Ignacio Arellano, Ildefonso Adeva y Rafael Zafra, Kassel, Reichenberger, 1995.

Calderón de la Barca, Pedro, La vacante general, en Autos sacramentales, III, ed. Enrique Rull Fernández, Madrid, Biblioteca Castro, 2001, pp. 325-383.

Calderón de la Barca, Pedro, La gran Cenobia, en Comedias, I, ed. Luis Iglesias Feijoo, Madrid, Biblioteca Castro, 2006, pp. 307-396.

Calderón de la Barca, Pedro, El médico de su honra, ed. Ana Armendáriz Aramendía, Madrid / Frankfurt, Iberoamericana / Vervuert, 2007.

Calderón de la Barca, Pedro, En la vida todo es verdad y todo mentira, en Comedias, III, ed. Don W. Cruickshank, Madrid, Biblioteca Castro, 2007, pp. 17-144.

Calderón de la Barca, Pedro, La hija del aire, en Comedias, III, ed. Don W. Cruickshank, Madrid, Biblioteca Castro, 2007, pp. 591-804.

Di Felice, Elena Sala, «Zeno, Apostolo», en The New Grove Dictionary of Opera, $I V$, ed. Stanley Sadie, New York, Macmillan, 1997, pp. 1226-1229.

Freeman, Robert, Opera without drama. Currents of change in italian opera, 16751725, Ann Arbor, UMI Research Press, 1981.

Kimbell, David, Italian Opera, Cambridge, Cambridge University Press, 1995.

Negri, Franceso, Vita di Apostolo Zeno, Venezia, Alvisopoli, 1816.

Sтrонм, Reinhard, Dramma per musica: Italian opera seria in the eighteenth century, Yale, Yale University Press, 1997.

Van Der Linden, Huub, «Apostolo Zeno as reader and (re)writer: acknowledgement of influence and anxiety of authorship", en The Books of Venice/ Il libro veneziano (Miscellanea Marciana, 2005-2007), ed. Lisa Pon y Craig Kallendorf, New Castle, Oak Knoll Press, 2009, pp. 383-410.

Zeno, Apostolo, Gl'inganni felici, Venezia, Marino Rossetti in Merceria all'Insegna della Pace, 1722.

Zeno, Apostolo, Griselda, Brusselle, Con Privilegio Cesareo, 1728. 
Zeno, Apostolo, Gianguir, en Poesie drammatiche di Apostolo Zeno, II, Venezia, Giambatista Pasquali, 1744, pp. 183-279.

Zeno, Apostolo, Semiramide in Ascalona, en Poesie drammatiche di Apostolo Zeno, II,Venezia, Giambatista Pasquali, 1744, pp. 365-443.

Zeno, Apostolo, Teuzzone, en Poesie drammatiche di Apostolo Zeno, III, Orléans, Couret de Villeneuve, 1785, pp. 89-176.

Zeno, Apostolo, Atenaide, en Drammi scelti di Apostolo Zeno, Venezia, Antonio Zatta e figli, 1790, pp. 161-246. 